\title{
Integrated Process Planning and Scheduling and Multimode Resource Constrained Project Scheduling: Ship Block Assembly Application
}

\author{
Raad Yahya Qassim \\ Department of Ocean and Naval Engineering, COPPE, \\ Federal University of Rio de Janeiro \\ Brazil
}

\section{Introduction}

Planning and scheduling are two major tasks in manufacturing system management, which have a direct bearing on the competitive position of enterprises inserted in diverse manufacturing fields, such as the chemical, aerospace, semiconductor, and shipbuilding industries. Inadequate planning and scheduling are considered to be a major cause of the gap between desired and actual enterprise manufacturing performance in terms of inventory level, throughput, manufacturing cost, and facility location. In order to bridge this gap, not only a feasible but also an optimal production network and supply chain schedule is required, which satisfies all types of constraints within the manufacturing marketing environment, with a view to achieving what has become known as enterprisewide optimisation (EWO). Until the start of the last decade, the focus of most multiple facility production firms operating at multiple sites has been on operations optimisation at the single facility level. Solutions obtained at this level are suboptimal at the multiple facility level. In order to obtain an optimal solution at the latter level, the scope of optimisation must be enlarged to model the multiple facility supply chain of the enterprise as a whole, including the interaction with suppliers and customers; see for example (Laínez et al., 2010), Munõz et al. , (2011), Stray et al., (2006), and Monostori et al., (2010).

Within EWO, there exists a wide spectrum of optimisation problems whose nature depends on the type of manufacturing environment that is under consideration. The concern in this paper is focused on two such problems:

1. integrated process planning and scheduling problem (IPPSP);

2. multimode resource-constrained project scheduling problem (MRCPSP).

In view of their important role in manufacturing management practice, this pair of problems has attracted significant interest in the academic literature. In the IPPSP, the two functions of process planning and production scheduling, which have usually been solved sequentially, are integrated and solved simultaneously, with a view to providing greater flexibility at the factory floor level. In the MRCPSP, the schedule of a project is obtained allowing each activity one or more modes of execution, whereby with each mode a time duration, 
execution cost, and resource consumption level are associated. For recent surveys of the IPPSP and MRCPSP, the reader may refer to (Shen et al., 2006) and (Hartmann \& Briskorn, 2010), respectively. The IPPSP arises normally at the shop floor level in batch process and discrete part manufacturing environments. The MRCPSP occurs in project - oriented production environments, such as those in shipbuilding, aerospace, and highway construction; see (Martínez et al., 1997 and Martínez \& Pérez, 1998). The general objective of this paper is to relate these two hitherto separately considered problems in manufacturing system management, in order to open vistas for the formulation and solution of new problem variants, which may benefit from the employment of methods and techniques that have been already developed separately for the IPPSP and MRCPSP. A specific application is provided by the development of a mathematical programming model for ship block assembly, which is one of the major final stages in shipbuilding; see for example ( Yu-guang et al., 2011).

\subsection{Integrated process planning and production scheduling problem}

In discrete manufacturing system management, two major tasks are process planning and production scheduling. In process planning, the question of how an item will be manufactured is answered. This is done by the determination of the sequence of operations that are necessary to produce the item under consideration. An item may be a part or an assembly of several parts. In general, an item may be manufactured in number of ways. This leads to the existence of a multiplicity of process plans. On the other hand, the question that has to be answered in production scheduling is the following: when is a job be dispatched to the shop floor, and what amount of each resource is allocated for its manufacture under prevailing conditions at a specific instant of time?

In general, process planning consists of the determination of operations and parameters that are required to convert raw materials or intermediate items into a finished item, such as a part or an assembly. The process planning task comprises the interpretation of design data, selection and sequencing of operations to manufacture the item, selection of machines, tools, and other resources, along with the corresponding quantitative data such as machine speeds and resource amounts. It is common practice that process planning is carried out in two stages: preliminary and detailed, whereby feasible process plans and optimal process plans are generated, respectively. Specific aspects of process planning vary with the application environment, such as machining, welding, and assembly; see, for example (Kong et al., 2011).

Production scheduling is normally carried out for several time horizon spans and corresponding levels of detail. This approach is known as hierarchical production planning (HPP); see, for example, (Bang \& Kim 2010). At the shortest time horizon span with corresponding most extensive level of detail, stands the shop floor scheduling problem, which is the focus of this paper. Here, one has a set of jobs, each of which possesses its own set of process plans, along with available resource amounts at the shop floor level. One requires the sequencing of jobs in time and the corresponding allocation of resources to each job; see, for example, (Li, et al., 2010).

In practice, the tasks of process planning and production scheduling are carried out sequentially, whereby for each item a set of alternative process plans are first determined. The generation of each process plan of an item is based on the assumption of the unlimited availability of the set of resources that are necessary for the execution of the plan on the shop 
floor. For each operation within a process plan, an execution time and an amount of each resource that is required for its execution, are associated. In the sequential approach, one member of the set of process plans so generated is selected according to one or more criteria, such as execution cost and execution time. Once the process plan selection problem is solved, and the process plan is fixed for each item, the production scheduling task is carried out for a set of jobs, each of which corresponds to an item, employing available resource amounts on the shop floor. This decomposition of the overall problem into a sequence of two subproblems for the generation of process plans and production schedules defines the sequential approach.

The sequential approach possesses the undeniable advantage of the simplification by decomposition of a large problem into a pair of smaller subproblems; however, the decomposition constitutes in essence a heuristic, in that the solution that it provides is an approximation to the solution of the original process planning / production scheduling problem. As a heuristic, it may provide adequate solutions albeit not optimal. In fact, an optimal solution can only be envisaged if a simultaneous approach is adopted, whereby the original problem is attacked without its decomposition into a pair of subproblems. This has become to be known as the integrated process planning and scheduling (IPPSP). Clearly, the simultaneous approach, whilst providing an optimal solution, involves a larger and therefore more difficult problem than that involved in the sequential approach. An additional and important practical advantage of the simultaneous approach is that under certain conditions in the shop floor, it may provide feasible solutions when this is not possible with the sequential approach. An example of this arises when job due dates are excessively tight when process plans are fixed prior to job arrival on the shop floor, as is the case in the sequential approach. In contrast, in the simultaneous approach, the degree of freedom provided by selecting process plans along with job production scheduling decisions may allow for meeting job due dates.

Having provided a motivation and a justification for research efforts on the IPPSP, the next question that arises pertains to its formulation and solution. A start is made by providing a typical problem statement of the IPPSP as follows. Given a set of independent jobs, with each of which a delivery due date is associated, that is to be manufactured employing one of a set of process plans, each of which consisting of a sequence of operations, with each of which a processing time and a set of resource amounts is associated, it is required to determine a minimum makespan production schedule. Clearly, in the IPPSP what is being sought is an optimal schedule. Consequently, mathematical programming (MP) provides a natural framework for the formulation and solution of the IPPS problem. Extensive work has been reported on variants of the IPPSP employing MP models; see (Li, et al., 2010) for further details.

\subsection{Multimode resource constrained project scheduling}

A major task in project management is project scheduling whose objective is the sequencing of project activities, which may be executed in one or more modes, subject to logical precedence between activities and limited resources. This has given rise to the resource constrained project scheduling problem (RCPSP). Extensive work has been carried out on the RCPSP; see [5] for a recent literature review. An important extension of the RCPSP is the multimode variant (MRCPSP), whereby an activity may be executed in more than one mode, whereby mode is a proxy for intensity, in that the activity work content may be executed at various speeds and corresponding resource consumption rates. 
A typical problem statement of the MRCPSP may be provided as follows. Given a project that consists of a set of activities with a corresponding set of logical precedence relations, a set pair of renewable and nonrenewable resources, it is required to determine a minimum makespan schedule. Obviously, the goal is the generation of an optimal schedule, and for this mathematical programming (MP) constitutes a natural framework for the formulation and solution of the MRCPSP. An extensive literature exists on MP modeling of the MRCPSP; see (Hartmann \& Briskorn, 2010), for a recent review.

\section{Process plan - Execution mode relation}

The similarity between two a priori different problems that arise in manufacturing systems management, IPPSP and MRCPSP, stems from the analogous roles of process plan and activity mode in the IPPSP and MRCPSP tasks, respectively. A job that is to be produced may be viewed as an activity to be completed, whilst a process plan corresponds to an execution mode. Extending the analogy, multiple jobs correspond to multiple projects in the corresponding environment.

If on the one hand, a process plan is similar to an execution mode, there exists an important conceptual difference. The former consists of a set of operations which possesses a corresponding set of precedence relations, whilst the latter is indivisible. Nevertheless, this conceptual difference results in practical implications when MP models are formulated and solved for the IPPSP and MRCPSP. In particular, the number of constraints in the former is higher in the IPPSP than in the MRCPSP of equal size, due to the existence of precedence relations in a process plan as opposed to the indivisibility of an execution mode. On a closer look, this difference may be conveniently removed if one considers the division of activities into subactivities, as suggested in (Nicoletti \& Nicoló, 1998). The introduction of the concept of subactivity may not be merely semantic, as it may possess a practical aspect, such as activity preemption. The interruption of activities has been shown to provide a manner of fast tracking. In practice, an activity may only be interrupted at a finite number of points during its execution. These points may serve as a useful basis for the definition of subactivities.

\section{Ship block assembly}

Normally, the assembly of a ship block is part of a shipbuilduing project, which comprises several blocks. As a result, the assembly of each block should be appropriately scheduled, so as to be compatible with the schedule of the shipbuilding project as a whole. In general, it is desirable to determine the earliest delivery date of each block. The problem of interest then is to determine the minimum makespan assembly schedule for each block. This problem may be viewed as a project scheduling problem with resource and material supply constraints; see, for example, Dodin \& Elimam, 2001, Alfieri et al., 2010, and Sajadieh, et al., 2009.

The following assumptions are made with a view to facilitating modelling of the problem.

1. With each activity, a duration time and a set of direct predecessor activities, and a set of direct successor activities are associated.

2. With each activity, a set of non - renewable resources, these being materials, is associated, this set being necessary to start and finish the activity.

3. With each member of the material set, a procurement lead time and a spatial area are associated, this set being necessary to start and finish the activity. 
4. With each activity, a set of renewable resources, such as spatial area and manpower, is associated.

Spatial area, which is a member of the set of renewable resources, is employed for two purposes: execution of an activity and storage of associated materials from delivery time to the start time of the execution of the activity.

The following notation is employed:

$i, j$ - indices for activities; $i \in I$

$\mathrm{k}$ - index for non-spatial area renewable resource; $\mathrm{k} \in \mathrm{K}$

$\mathrm{m}$ - index for non-renewable material source; $\mathrm{m} \in \mathrm{M}$

$\mathrm{n}$ - index for spatial area renewable resource; $\mathrm{n}=1$

$\mathrm{t}$ - index for time period; $\mathrm{t} \in \mathrm{T}$

$\mathrm{D}_{\mathrm{i}}$ - duration time of activity $\mathrm{i}$

$\mathrm{EF}_{\mathrm{i}}$ - earliest finish time of activity $\mathrm{i}$

$\mathrm{ES}_{\mathrm{i}}$ - earliest start time of activity i

$\mathrm{F}_{\mathrm{i}}$ - set of direct predecessor activities of activity $\mathrm{i}$

$\mathrm{G}_{\mathrm{m}}$ - lead time material $\mathrm{m}$

$\mathrm{H}_{\mathrm{imn}}$ - spatial area renewable resource $\mathrm{n}$ required by material $\mathrm{m}$ associated with activity $\mathrm{i}$

$\mathrm{LF}_{\mathrm{i}}$ - latest finish time of activity $\mathrm{i}$

$\mathrm{LS}_{\mathrm{i}}$ - latest start time of activity $\mathrm{i}$

$P_{i k}$ - non-spatial area renewable resource per unit time required by activity $\mathrm{i}$

$\mathrm{Q}_{\mathrm{n}}$ - available non - spatial area renewable resource $\mathrm{n}$

$\mathrm{R}_{\mathrm{mt}}$ - inventory level of material non - renewable resource $\mathrm{m}$ in time period $\mathrm{t}$

$S_{n}$ - available spatial area renewable resource $n$

$X_{i t}$ - binary variable $\in\{1$ if activity $i$ is finished in time period $t, 0$ otherwise $\}$

$\mathrm{Y}_{\text {it }}$ - binary variable $\in\{1$ if activity $\mathrm{I}$ is in execution in time period $t, 0$ otherwise $\}$

$\mathrm{Z}_{\mathrm{imt}}$ - binary variable $\in\{1$ if material $\mathrm{m}$ associated with activity $\mathrm{I}$ is ordered in time period $\mathrm{t}$, 0 otherwise \}

The model may be stated as follows.

$$
\text { Minimise } \Sigma_{\tau=\text { EFI,...LFI }} \tau X_{\mathrm{I} \tau}
$$

subject to

$$
\begin{gathered}
\sum_{\tau=\mathrm{EFj}, \ldots, \mathrm{LFj}} \tau \quad \mathrm{X}_{\mathrm{j} \tau}+\mathrm{D}_{\mathrm{i}} \leq \Sigma_{\tau=\mathrm{EFi}, \ldots, \mathrm{LFi}} \tau \mathrm{X}_{\mathrm{i} \tau}, \forall \mathrm{j} \in \mathrm{F}_{\mathrm{i}} ; \forall \mathrm{i} \in \mathrm{I}, \\
\sum_{\tau=1, \ldots, \mathrm{T}} \tau \quad \mathrm{Z}_{\mathrm{im} \tau} \leq \sum_{\tau=\mathrm{EFi}, \ldots, \mathrm{LFi}} \tau \mathrm{X}_{\mathrm{i} \tau}-\mathrm{D}_{\mathrm{i}}-\mathrm{G}_{\mathrm{m}}, \forall \mathrm{i} \in \mathrm{I} ; \forall \mathrm{m} \in \mathrm{M}, \\
\sum_{\mathrm{i} \in \mathrm{I}} \mathrm{P}_{\mathrm{ik}} \mathrm{Y}_{\mathrm{it}} \leq \mathrm{Q}_{\mathrm{k}}, \forall \mathrm{k} \in \mathrm{K} ; \forall \mathrm{t} \in \mathrm{T}, \\
\sum_{\mathrm{m} \in \mathrm{M}} \quad \mathrm{R}_{\mathrm{mt}} \leq \mathrm{S}_{\mathrm{n}}, \forall \mathrm{t} \in \mathrm{T}, \\
\mathrm{R}_{\mathrm{mt}}=\mathrm{R}_{\mathrm{m}, \mathrm{t}-1}+\sum_{\mathrm{i} \in \mathrm{I}} \mathrm{H}_{\mathrm{imn}}\left(\mathrm{Z}_{\mathrm{im}, \mathrm{t}-\mathrm{Gm}}-\mathrm{X}_{\mathrm{it}}\right), \forall \mathrm{m} \in \mathrm{M} ; \forall \mathrm{t} \in \mathrm{T}, \\
\mathrm{R}_{\mathrm{m} 0}=0, \forall \mathrm{m} \in \mathrm{M}, \\
\sum_{\tau=\mathrm{EFi}, \ldots, \mathrm{LFi}} \mathrm{X}_{\mathrm{i} \tau}=1, \forall \mathrm{i} \in \mathrm{I},
\end{gathered}
$$




$$
\begin{gathered}
\Sigma_{\tau=\mathrm{EFi}, \ldots, \mathrm{LFi}} \mathrm{Y}_{\mathrm{i} \tau}=\mathrm{D}_{\mathrm{i}}, \forall \mathrm{i} \in \mathrm{I}, \\
\Sigma_{\tau=1, \ldots, \mathrm{T}} \mathrm{Z}_{\mathrm{im} \tau}=1, \forall \mathrm{i} \in \mathrm{I} ; \forall \mathrm{m} \in \mathrm{M}, \\
\mathrm{X}_{\mathrm{it}}, \mathrm{Y}_{\mathrm{it}}, \mathrm{Z}_{\mathrm{imt}} \in\{0,1\}, \forall \mathrm{i} \in \mathrm{I} ; \forall \mathrm{m} \in \mathrm{M} ; \forall \mathrm{t} \in \mathrm{T} .
\end{gathered}
$$

Expression (1) defines the project makespan objective function that is to be minimised. Constraints (2) ensure precedence between an activity and each of its direct predecessor activities. Constraints (3) ensure that all materials necessary for each activity are available before the start of an activity. Constraints (4) and (5) guarantee that each renewable resource is not exceeded in each time period. Constraints (6) ensure the material balance over the planning horizon. Constraints ( 7) fix the initial inventory level of each material at the start of the planning horizon. Constraints (8) ensure that an activity is finished once in the planning horizon. Constraints (9) define the time duration of each activity. Constraints (10) guarantee that each material is ordered once for each activity over the planning horizon. Constraints (11) define the domain of the decision variables.

\subsection{Three - level assembly problem}

Consider for illustrative purposes the three - level block assembly example shown in Fig.1. This problem possesses features which belong to both the IPPSP and MRCPSP. As it arises in shipbuilding practice, it is naturally viewed as a variant of the IPPSP. With a view to highlighting the connection with the MRCPSP, it is modelled in this Subsection as belonging to the MRCPSP. The initial and final activities are denoted by $i=0$ and $i=8$, respectively. It is assumed that there exists a single non-spatial renewable resource, namely manpower, and it is denoted by $\mathrm{k}=1$; furthermore, it is assumed that the spatial area renewable resource is common to all activities and materials in the assembly workshop and it is denoted by $n=1$. The model of this example may be stated as follows.

$$
\text { Minimise } \Sigma_{\tau=\mathrm{EF} 8, \ldots, \mathrm{LFT} 8} \tau \mathrm{X}_{8 \tau},
$$

subject to

$$
\begin{aligned}
& \sum_{\tau=\mathrm{EF} 0, \ldots, \mathrm{LF} 0} \tau \mathrm{X}_{0 \tau}+\mathrm{D}_{1} \leq \Sigma_{\tau}=\mathrm{EF} 1, \ldots, \mathrm{LF} 1 \quad \tau \mathrm{X}_{1 \tau}, \\
& \Sigma_{\tau=1, \ldots, \mathrm{T}} \tau \mathrm{Z}_{11 \tau} \leq \tau \mathrm{X}_{1 \tau}-\mathrm{D}_{1}-\mathrm{G}_{1}, \\
& \sum_{\mathrm{i}=1, \ldots, 8} \mathrm{P}_{\mathrm{i} 1} \mathrm{Y}_{1 \mathrm{t}} \leq \mathrm{Q}_{1}, \\
& \Sigma_{\mathrm{m}=1, \ldots, 8} \quad \mathrm{R}_{\mathrm{m} 1} \leq \mathrm{S}_{1},
\end{aligned}
$$

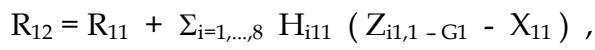

$$
\begin{aligned}
& \mathrm{R}_{10}=0 \text { ， } \\
& \sum_{\tau=\mathrm{EF} 1, \ldots, \mathrm{LF} 1} \mathrm{X}_{1 \tau}=1 \text {, } \\
& \Sigma_{\tau}=\mathrm{EF} 1, \ldots, \mathrm{LF} 1 \quad \mathrm{Y}_{1 \tau}=\mathrm{D}_{1}, \\
& \Sigma_{\tau=\mathrm{EF} 1, \ldots, \mathrm{LF} 8} \mathrm{Z}_{11 \tau} .
\end{aligned}
$$




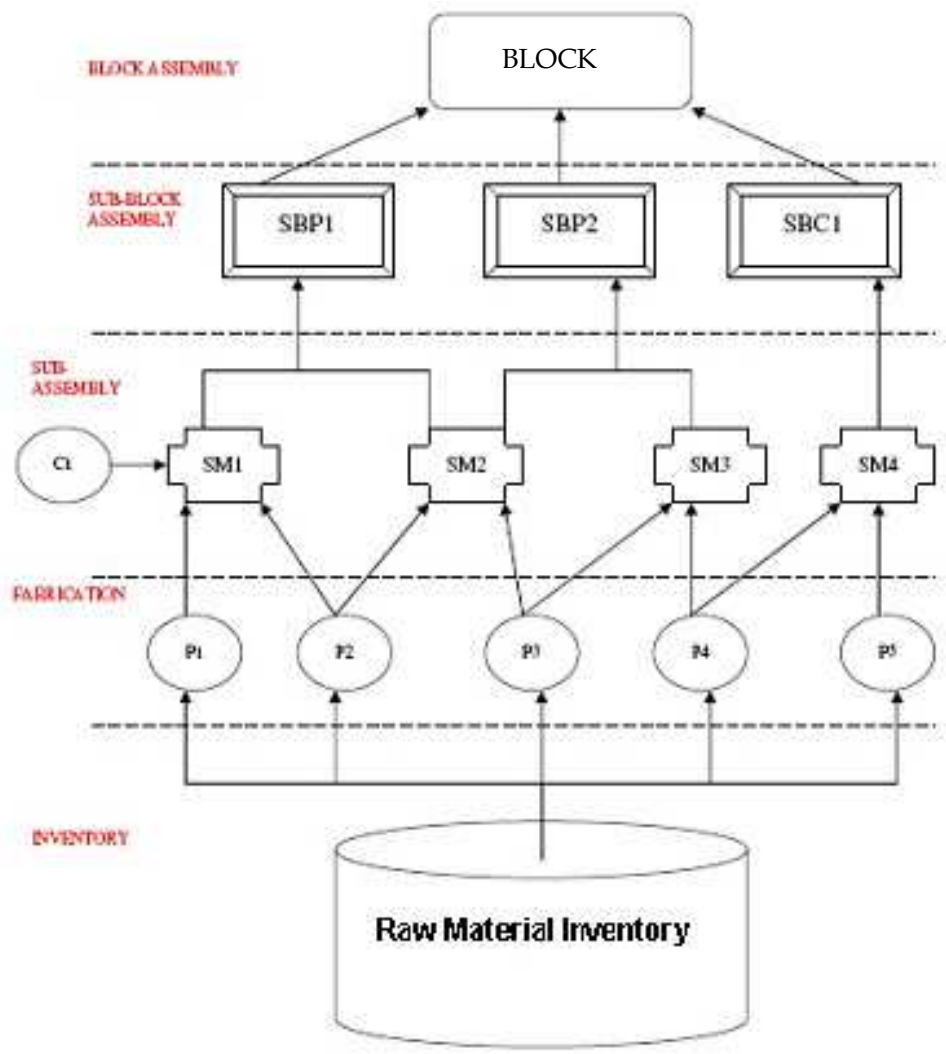

Legend:

P1 - material 1

P2 - material 2

$\mathrm{P} 3$ - material 3

P4 - material 4

P5 - material 5

C1 - material 6

SM1 - activity 1

SM2 - activity 2

SM3 - activity 3

SM4 a- activity 4

SBP1 - activity 5

SBP2 - activity 6

SBC1 - activity 7

BLOCK - activity 8

Fig. 1. Three - level assembly example.

\section{Conclusions}

In this paper, the relation between two problems, IPSS and MRCPSP, arising in manufacturing systems management, which have been formulated and solved by separate mathematical programming modeling approaches, have been shown to possess clear similarity features. This similarity has not been explored, and therefore there exists a clear potential for the interplay of methods and techniques between the two problems. These include novel model formulations and solution strategies for the IPPSP and MRCPSP variants, such as dynamic shop floor scheduling and project rescheduling (Ouelhadj \& Petrovic, 2009), (Gerk \& Qassim, 2008). This provides a rich field to be explored by future research work, a start having been made in a recent paper (Capek et al., 2011).

\section{Acknowledgements}

The author wishes to acknowledge financial support, in the form of a research fellowship, of the Brazilian National Research and Development council, CNPq. Recommendations and suggestions by an anonymous referee with a view to improving the paper are gratefully acknowledged. 


\section{References}

Alfieri, A., Tolio, T., Urgo, M. (2010) A Project scheduling approach to production and material requirement planning in Manufacturing-to-Order environments. Journal of Intelligent Manufacturing, DOI 10.1007/s10845-010-0396-1.

Bang, J.-Y.; Kim, Y.-D. (2010). Hierarchical production planning for semiconductor water fabrication based on linear programming and discrete - event simulation. IEEE Transactions on Automation Science and Engineering, vol.7, no.2, pp,326-336.

Capek, R.; Sucha, P.; Hanzálek, Z. (2011). Production scheduling with alternative process plans. European Journal of Operational Research, doi: 10.1016/j.ejor.2011.09.018.

Dodin, B., Elimam, A.A. (2001) Integrated project scheduling and material planning with variable activity duration and rewards. IIE Transactions, vol.33, pp.1005-1018.

Gerk, J. E. V.; Qassim, R. Y. (2008) Project acceleration via activity crashing, overlapping, and substitution. IEEE Transactions on Engineering Management, vol.55, no.4, pp. 590-601.

Hartmann, S.; Briskorn, D. (2010). A survey of variants and extensions of the resource - constrained project scheduling problem. European Journal of Operational Research, vol.207, pp.1-14.

Kong, F.; Zuo, J.; Zha, G.; Zhang, J. (2011). Study and application of open die forging CAPP system based on process knowledge. Journal of Advanced Manufacturing Systems, vol.10, no.1, pp.45-52.

Laínez, J.M.; Reklaitis, G.V.; Puigjaner, L. (2010). Linking marketing and supply chain models for improved business strategic decision support. Computers and Chemical Engineering, vol.34, pp.2107-2117.

Li, X.; Shao, X.; Zhang, C.; Wang, C. (2010). Mathematical modeling and evolutionary based approach for integrated process planning and scheduling. Computers and Operations Research, vol.37, pp.656-667.

Martínez, E. C., Duje, D., Pérez, G.A. (1997) On performance modeling of Project-oriented production. Computers and Industrial Engineering, vol.33, no.3, pp.509-527.

Martínez, E. C., Pérez, G. A. (1998) A project-oriented production model of batch plants. Computers and Chemical Engineering, vol.22, no.3, pp.391-414.

Monostori, L., Edos, G., Kádár, B., Kis, T., Kovács, A., Pffeifer, A., Váncza, A. (2010) digital enterprise solution for integrated production planning and control. Computers in Industry, vol.61, pp.112-126.

Munõz, E.; Capón-Garcia, E.; Moreno-Benito, M.; Espuña, A.; Puigjaner, L. (2011). Scheduling and control decision-making under an integrated information environment. Computers and Chemical Engineering, vol.35, pp.774-786.

Nicoletti, S., Nicoló, F. (1998). A concurrent engineering decision model : Management of the project activities information flow. International Journal of Production Economics, vol.54, pp.115-127.

Ouelhadj, D.; Petrovic, S. (2009). A survey of dynamic scheduling in manufacturing systems. Journal of Scheduling, vol.12, pp.417-431.

Sajadieh, M.S., Shadrkh, S., Hassanzadeh, F. (2009) Concurrent project scheduling and material planning: A genetic algorithm approach. Scientia Iranica, vol. 16, pp.91-99.

Shen, W.; Wang, L.; Hao, Q. (2006). Agent-based distributed manufacturing process planning and scheduling: A state - of - the - art survey. IEEE Transactions on Systems, Man, and Cybernetics - Partt C: Applications and Reviews, vol.36, no.4, pp.563-577.

Stray, J.; Fowler, J.W.; Carlyle, W.M.; Rastogi, A.P. (2006). Enterprise-wide semiconductor resource planning. IEEE Transactions on Semiconductor Manufacturing, vol.19, no.2, pp.259-268.

Yu-guang, Z., Kai, X., Yong, Z. (2011). Modeling and analysis of panel hull block assembly system through time colored petri net. Marine Structures, vol.24, no.4, pp.570-580. 


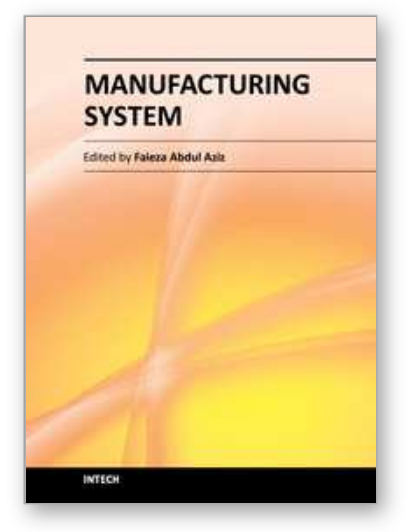

\author{
Manufacturing System \\ Edited by Dr. Faieza Abdul Aziz
}

ISBN 978-953-51-0530-5

Hard cover, 448 pages

Publisher InTech

Published online 16, May, 2012

Published in print edition May, 2012

This book attempts to bring together selected recent advances, tools, application and new ideas in manufacturing systems. Manufacturing system comprise of equipment, products, people, information, control and support functions for the competitive development to satisfy market needs. It provides a comprehensive collection of papers on the latest fundamental and applied industrial research. The book will be of great interest to those involved in manufacturing engineering, systems and management and those involved in manufacturing research.

\title{
How to reference
}

In order to correctly reference this scholarly work, feel free to copy and paste the following:

Raad Yahya Qassim (2012). Integrated Process Planning and Scheduling and Multimode Resource Constrained Project Scheduling: Ship Block Assembly Application, Manufacturing System, Dr. Faieza Abdul Aziz (Ed.), ISBN: 978-953-51-0530-5, InTech, Available from:

http://www.intechopen.com/books/manufacturing-system/integrated-process-planning-and-scheduling-andmultimode-resource-constrained-project-scheduling-shi

\section{INTECH}

open science | open minds

\section{InTech Europe}

University Campus STeP Ri

Slavka Krautzeka 83/A

51000 Rijeka, Croatia

Phone: +385 (51) 770447

Fax: +385 (51) 686166

www.intechopen.com

\section{InTech China}

Unit 405, Office Block, Hotel Equatorial Shanghai

No.65, Yan An Road (West), Shanghai, 200040, China

中国上海市延安西路65号上海国际贵都大饭店办公楼405单元

Phone: +86-21-62489820

Fax: $+86-21-62489821$ 
(C) 2012 The Author(s). Licensee IntechOpen. This is an open access article distributed under the terms of the Creative Commons Attribution 3.0 License, which permits unrestricted use, distribution, and reproduction in any medium, provided the original work is properly cited. 